\title{
O PAPEL DA LINGUAGEM NA OBRA VERDADE E MÉTODO DE HANS-GEORG GADAMER
}

\section{Susan Karolaine Gonçalves Soares Barbosa}

Resumo: O presente artigo pretende discorrer acerca do papel da linguagem, enquanto fenômeno ontológico, na hermenêutica filosófica promovida por Hans-Georg Gadamer. A temática é proposta a partir da discussão sobre em que medida a linguagem encontra-se conectada com a tradição, o questionamento que movimenta a intenção da pesquisa é conduzido com a intenção de reconhecer a correspondência entre linguagem e tradição. Deste modo, visase apresentar no âmbito da experiência hermenêutica a ligação entre os conceitos de linguagem e tradição que resulta no acontecer de uma verdade compreensiva. A partir da obra Verdade e Método (1960) a presente investigação abarca a concepção do autor no que tange o conceito da verdade como resultado do processo compreensivo e, o coloca em movimento ao não ser mais diretamente conectado ao âmbito científico. A verdade encontra-se, portanto, vinculada à linguagem, onde ganha novos horizontes.

Palavras-chave: Linguagem. Hermenêutica Filosófica. Tradição.

\begin{abstract}
The present article intends to deal with the role of language, as an ontological phenomenon, in the philosophical hermeneutics promoted by Hans-Georg Gadamer. The theme is proposed from the discussion about how language is connected with tradition, the questioning that moves the intention of the research is conducted with the intention of recognizing the correspondence between language and tradition. In this way, it is intended to show within the hermeneutic experience the connection between the concepts of language and tradition that results in the realization of a comprehensive truth. From the book Truth and Method (1960) this investigation covers the author's conception of the concept of truth as a result of the comprehensive process and sets him in motion by no longer being directly connected to the scientific field. The truth is linked to language, where it gains new horizons.
\end{abstract}

Keywords: Language. Philosophical Hermeneutics. Tradition.

\footnotetext{
${ }^{1}$ Graduada em Licenciatura em Filosofia pela Universidade do Estado do Pará (UEPA). Atualmente, mestranda no Programa de Pós-Graduação em Filosofia da Universidade Federal do Pará (PPGFIL-UFPA), na linha de pesquisa: "Estética, Ética e Filosofia Política" sob a orientação do Professor Dr. Roberto de Almeida Pereira de Barros. Integra o Grupo de Pesquisa Temática em Filosofia Contemporânea da Universidade Federal do Pará. Currículo Lattes: http://lattes.cnpq.br/3701548745138495.
} 


\section{Introdução}

Este artigo tem como objetivo expor o papel da linguagem na obra Verdade e Método de Hans-Georg Gadamer. Para isso, é necessário abordar os aspectos da filosofia gadameriana, São caros à discussão proposta os conceitos de tradição, autoridade, historicidade do ser como condições para o processo compreensivo. Tal percurso é fundamental para alcançar a relação entre linguagem e tradição que tem como resultado a verdade compreensiva, partindo da condição ontológica da linguagem e da hipótese que linguagem é tradição. Com isso, além de explicitar a linguagem enquanto fenômeno ontológico de todo o processo compreensivo, constitui-se também como tarefa investigar a historicidade do ser para repensar a experiência hermenêutica.

O primeiro momento do texto tem como objetivo expor os aspectos básicos da hermenêutica filosófica de Gadamer, dessa forma, fica evidenciada a áspera relação do autor com o movimento iluminista, designado no corpo do texto como Aufklarung. Essa relação é o cenário sob o qual é possível discutir, de forma detalhada, o processo interpretativo na filosofia gadameriana e torna compreensível o percurso que o autor realiza para a elaboração de uma hermenêutica filosófica. O segundo momento do texto expõe a condição ontológica da linguagem, trata-se de apresentar a linguagem enquanto fulcral à experiência hermenêutica, ela é o solo de todo o processo interpretativo. É desvelado nesse desenvolvimento a relação entre o humano e a linguagem. $O$ terceiro momento do texto expõe a concepção de verdade segundo Gadamer, ou seja, o resultado do entendimento da linguagem enquanto solo do processo interpretativo, é demonstrado o aparecimento de uma verdade compreensiva que se movimenta em uma dinâmica dialógica e, portanto, está intimamente ligada à linguagem.

\section{Aspectos básicos da hermenêutica filosófica de Hans-Georg Gadamer.}

Gadamer se posiciona contra a Aufklarung", afirmando que: "Uma análise da história do conceito mostra que somente na Aufklarung que o conceito do preconceito recebeu o matiz negativo que agora possui” (GADAMER, 2016, p. 360). Segundo o autor, o conceito do preconceito significa juízo (Urteil), ou melhor, um julgamento anterior a conclusão definitiva em torno de algo, conceber o real problema hermenêutico é identificar todas as dimensões

\footnotetext{
${ }^{2}$ Este termo deve ser lido como movimento do Iluminismo, Gadamer trata da existência de uma Aufklarung antiga proveniente da filosofia grega e de uma Aufklarung moderna, esta última será a base das críticas feitas pelo autor acerca dos conceitos de tradição e preconceito.
} 
intrínsecas da compreensão, inclusive no que tange os preconceitos, ou seja, o primeiro passo do processo interpretativo é reconhecer o viés positivo desse conceito, esse é o ponto de partida do processo hermenêutico gadameriano.

Dessa forma, afirma Gadamer (2016, p. 368): “os preconceitos de um indivíduo, muito mais que seus juízos constituem a realidade histórica do seu ser”. No entanto, para dar-se conta desse contexto permeado, também, por dimensões anteriores a dinâmica da compreensão, o outro deve se fazer presente, e o eu, deve estar receptivo ao seu horizonte que é distinto, portanto, é no contato com o outro que torna-se possível reconhecer as dimensões que precedem o eu.

Nosso ponto de partida, portanto, para a problemática da hermenêutica está nos pontos danificados da concepção errônea concebida pela Aufklärung no que tange o conceito do preconceito, que desfigurou também os conceitos da autoridade e da tradição. Gadamer define a autoridade enquanto:

Uma atribuição a pessoas. Mas a autoridade das pessoas não tem seu fundamento último num ato de submissão e de abdicação da razão, mas num ato de reconhecimento e de conhecimento: reconhece-se que o outro está acima de nós em juízo e visão e que, por consequência, seu juízo precede, ou seja, tem primazia em relação ao nosso próprio juízo. Isso implica que, se alguém tem pretensões à autoridade esta não deve ser-lhe outorgada; antes, autoridade é e deve ser alcançada. (GADAMER, 2016, p. 371).

Gadamer propõe a reabilitação dos conceitos de pré-compreensibilidade (preconceito), tradição e autoridade, para isso através de uma análise fenomenológica, o autor buscou alcançar a essência desses fenômenos. A pré-compreensibilidade contribui no processo interpretativo através da legitimidade de sua estrutura, o conceito de autoridade tem como chave interpretativa o conceito de Anerkennung (reconhecimento), rejeitado como ordem, mas admitido enquanto aceitação da superioridade do outro. Gadamer conduz a reabilitação da autoridade e da tradição a partir da historicidade. A tradição, segundo o autor, é essencialmente transmissão, é "sempre um momento de liberdade e da própria história” (GADAMER, 2016, p. 373), dela parte preconceitos legítimos, e facilmente é colocada como sinônimo de razão.

A historicidade intrínseca da existência humana compõe o ponto de partida de Gadamer, bem como a consciência histórica (PALMER, 1969), a dimensão histórica na filosofia gadameriana é oriunda da dialética de Hegel, Gadamer, no entanto, não a incorpora integralmente, pois, rejeita o movimento absoluto proposto pela filosofia hegeliana, e de acordo com Stein (2014, p. 215), a substitui pela "historicidade do sentido". Não mais conectado com 
a via metodológica, a historicidade do ser ganha papel de destaque dentro do pensamento de Gadamer ao influenciar a compreensão do intérprete a partir da tradição na qual está inserido, essa localidade forja a condição anterior a compreensão. Assim, surge a pré-compreensão (précompreensibilidade) que é a estrutura que possibilita a própria compreensão e, portanto, abre caminho para diferentes compreensões conforme a tradição na qual o intérprete está inserido. Essa possibilidade torna inviável a existência de uma verdade absoluta, bem como, demonstra que com o ser histórico a tradição exerce grande poder ao validar a pré-compreensibilidade decorrente de sua posição.

A linguagem é definida como elemento universal que torna a hermenêutica menos epistemológica e mais ontológica, essa afirmação nos remete ao século XIX que permeado pelos questionamentos das possibilidades do conhecer, logo, das condições de objetividade voltadas para o conhecimento se torna um ambiente favorável para o florescer dos problemas ligados à historicidade, ou seja, a uma manifestação situada em determinado contexto histórico. Destaca-se, nesse momento, August Boeckh (1886) que levava em consideração a contextualização histórica do entendido, bem como, a interpretação gramatical, individual e psicológica.

Com Johann Gustav Droysen (2009) a reflexão crítica metodológica acerca da historicidade se intensifica, apesar de Droysen não tratar diretamente da hermenêutica o autor tornou o conceito de compreensão um marco central em seus escritos, uniu os conceitos de compreensão e investigação na tarefa de atuar no âmbito da historicidade, essa união "deve marcar a infinitude da tarefa [...] é só investigando a tradição até o fim e 'sem descanso', descobrindo sempre novas fontes e reinterpretando-as sem cessar, que a investigação vai se aproximando pouco a pouco da 'ideia"' (GADAMER, 2016, p. 292). Trata-se de uma compreensão essencialmente investigadora que nunca encontra um ponto final, assim como a história. Droysen entende que as ciências históricas necessitam de métodos próprios, pois o crescimento das ciências naturais se localiza no reconhecimento de seu objeto, bem como, no entendimento de suas possibilidades e limites acerca desse objeto a partir de um método próprio.

Esse percurso nos leva ao pensamento de Wilhelm Dilthey (1999), que tem como preocupação central uma metodologia voltada para a historicidade. Sua hermenêutica não se apresenta como instrumento para um fim, mas possui um papel fundamental na discussão das ciências do espirito. Assim como Droysen, a intenção de Dilthey é colocar as ciências do espirito em seu âmbito de atuação a partir de uma metodologia própria, para isso, é necessário 
usar como base a estrutura 'a priori' ligada em uma experiência interior, na qual encontramos respaldo para montar o campo próprio de pesquisa das ciências do espirito. A experiência interior requer, portanto, uma base sólida, que será desempenhada pela psicologia e tem a função de tornar evidente os fundamentos das ciências do espirito e garantir a objetividade do processo.

Com essa exposição foi intencionado deslindar a esfera epistemológica da hermenêutica, que encontra em Dilthey sua manifestação mais autêntica com o aumento da problemática hermenêutica para além da filologia, Jean Grodin (1999) afirma que nesse momento a hermenêutica ganha a problemática do conhecimento histórico, bem como, se insere no problema da objetividade do conhecer. É possível também, vislumbrar o início do deslocamento da hermenêutica do campo epistemológico para o campo ontológico com Heidegger e Gadamer, que se efetiva na linguagem, mas se inicia com o conceito de historicidade tornando possível a retirada do conceito de compreensão da esfera epistemológica do pensamento para a esfera ontológica do Ser.

Essa virada do campo epistemológico para o ontológico acontece sob a pretensão de colocar a filosofia como ponto central da discussão hermenêutica. A concepção de compreensão empreendida por Heidegger possui uma área denominada pré-estrutura da compreensão, e é por meio dessa estrutura que a compreensão se torna possível. Heidegger, de acordo com Ricoeur (1978), elabora uma hermenêutica da facticidade, que é um dos principais pontos levantados em sua filosofia, para tratar da realidade do homem, que também é analisada sob os conceitos da existencialidade e da ruína, o momento em que o homem se reduz diante das banalidades inclusas em seu cotidiano. A compreensão é, portanto, voltada para o fato de que é o ser-ai ou Dasein que diante da facticidade, se encontra jogado nas condições que envolvem seu mundo, logo, seu processo interpretativo se realiza nesse ambiente.

Com Heidegger a discussão interpretativa é conectada com a questão do Ser, é esse caráter ontológico que provoca a manifestação da estrutura da pré-compreensão, portanto, é dessa forma que se estabelece a dimensão filosófica da hermenêutica. Essa via ontológica tem como objetivo decifrar a relação do ser-no-mundo e, portanto, seu contexto, trata-se de uma ontologia da compreensão que foca na relação do ser-em, ou do eu na própria situação. Dessa forma, a filosofia é base do processo que constitui o Ser que reflete acerca do estar no mundo e sua condição neste. Compreender, portanto, é tomar conhecimento das possibilidades de manifestação do ser, mais relacionada a uma prática. Sobre o conceito de compreensão em Heidegger, afirma Gadamer: 
Compreender não é um ideal resignado da experiência de vida humana na idade avançada do espirito, como em Dilthey; mas tampouco é, como em Husserl, um ideal metodológico último da filosofia frente à ingenuidade do ir vivendo. É, ao contrário, a forma originária de realização da pre-sença, que é ser-no-mundo. Antes de toda diferenciação da compreensão nas diversas direções do interesse pragmático ou teórico, a compreensão é o modo de ser da pre-sença, na medida que é poder-ser e possibilidade. (GADAMER, 2016, p. 347).

Quando Heidegger se apropria da temática do Ser, o relaciona à linguagem, o ser pode então ser visualizado a partir da linguagem, é nela que se encontra a relação hermenêutica por excelência. A linguagem tem o papel de manifestar o ser enquanto discurso voltado para a relação do ser-no-mundo. A pré-compreensão ganha movimento com o conceito do círculo hermenêutico, esse conceito contempla a nova forma do processo interpretativo, e ecoa no momento anterior da compreensão em si, bem como, no deslocamento entre o todo e as partes para estabelecer o ato interpretativo de forma sólida. Essa via ontológica tem por objetivo tornar compreensível a relação do ser-no-mundo, ou a relação do eu com seu contexto/situação.

Ainda que tenha recebido muita influência de Heidegger, a concepção gadameriana acerca do fenômeno da compreensão ganha uma forma inovadora de incorporar uma via filosófica, de tal maneira que o afastaria de sua maior influência. Ernildo Stein (2014, p. 208) afirma que: "a hermenêutica filosófica de Gadamer recuou diante das pretensões da filosofia hermenêutica de Heidegger", tal recuo não diminuiu as pretensões próprias da hermenêutica gadameriana que ao incorporar a via filosófica, o fez ampliando seu horizonte.

Abordar a experiência hermenêutica gadameriana é discutir uma nova forma de tratar o conceito de pré-compreensibilidade. É necessário, portanto, apontar a existência de preconceitos legítimos para de fato abarcar na experiência hermenêutica a finitude e a historicidade do ser. Diferentemente da Aufklärung, que designou uma noção negativa ao conceito do preconceito, Gadamer constrói uma visão positiva do conceito. De acordo com Almeida (2002) a tarefa da compreensão é adequar intérprete e texto concomitantemente aos pré-juízos inseridos, protegendo a diferença de ambos para que o confronto de ideias venha a resultar em verdadeiras possibilidades, torna-se importante destacar que o ato interpretativo nunca se encontra pronto e acabado, intérprete e interpretado estão igualmente inseridos no devir histórico do qual fazemos parte. Dessa forma, afirma Palmer (1969, p. 185-186): “os juízos prévios não são algo que devemos aceitar ou que possamos recusar; são a base da capacidade que temos para compreender a história”. 
A experiência hermenêutica correta se dá recepcionando o horizonte distinto que está proposto, longe da posição de neutralidade, mas compreendendo o seu lugar no ato. Faz-se necessário assimilar a pré-compreensibilidade do processo interpretativo, bem como, os juízos prévios, que também devem estar no processo, pois, garantem a instância histórica do ato, o intérprete deve, portanto, perceber-se inserido em uma tradição.

Dessa forma,

O compreender deve pensar-se menos como uma ação da subjetividade do que como um lançar-se para um acontecer da tradição em que o passado e o presente se encontram em contínua mediação. Isto é o que tem que se fazer ouvir na teoria hermenêutica, demasiadamente dominada até agora pela ideia de um procedimento, de um método. (GADAMER, 2016, p. 295).

Como já fora afirmado, a concepção acerca da pretensão da hermenêutica com Gadamer, deixa de ser de cunho metodológico e passa a ser ligado essencialmente a compreensão enquanto experiência humana do mundo (PALMER, 1969). O caminho para a compreensão se inicia na pergunta, logo a estrutura lógica de abertura para a experiência hermenêutica tem o formato de diálogo. Em torno disso, afirma Almeida (2002, p. 271): “A pergunta é a condição hermenêutica originária, porque com ela iniciamos o esforço hermenêutico, abrimos e mantemos abertas as possibilidades da compreensão". O diálogo ocorre na presença do outro, portanto, a partir do outro é possível reconhecer a própria finitude, nesse momento existem concepções diferentes, se interpelando e, consequentemente, projetando-se ao outro para possibilitar o compreender de si e do outro enquanto seres imersos no devir histórico.

\section{A condição ontológica na linguagem}

A linguagem no âmbito da hermenêutica filosófica de Gadamer é de extrema importância, pois, é a linguagem que irá agir como fio condutor da experiência hermenêutica. Conceber, portanto, o conceito de linguagem enquanto possuidor de uma condição ontológica é afirmar seu papel de solo em todo o processo hermenêutico.

É a linguagem o verdadeiro centro do ser humano, quando se a vê apenas naquele domínio que só ela preenche, o domínio de estar com o outro, o domínio da compreensão, tão imprescindível à vida humana quanto o ar que respiramos. O homem é realmente como disse Aristóteles, o ser dotado de linguagem. Por isso tudo que é humano, nós devemos deixar que se nos seja dito. (ALMEIDA; FLICKINGER; ROHDEN, 2000, p. 127).

A partir dessa ligação direta entre a essência do homem e a linguagem é possível afirmar que "a linguística e o conteúdo transmitido não podem se separar da experiência hermenêutica" 
(ALMEIDA, 2002, p. 204). Seria errôneo, portanto, colocar a linguagem como instrumento no pensamento de Gadamer, não nos conectamos ao mundo fazendo uso da linguagem como ferramenta, pois isso culminaria em retornar à concepção da possibilidade de compreensão total, propõe-se então uma concepção de compreensão aberta, na qual não existe um final absoluto para o ato compreensivo. A partir disso, conclui-se que a ligação intensa entre o ser humano e a linguagem é proveniente da imersão na e pela linguagem, que por sua vez nos sobrepuja, pois, "em nosso pensar e conhecer somos já sempre parciais devido à interpretação linguística do mundo" (ALMEIDA; FLICKINGER; ROHDEN, 2000, p. 122). Ao explanar acerca do que compete a linguagem Gadamer reúne três momentos que indicam o caráter universal da linguagem.

O primeiro momento é o autoconhecimento, que o autor ira nomear de vivacidade do falar, Gadamer indica que o que é próprio da estrutura da linguagem é esquecido a partir da realização da língua viva, ou seja, "quanto mais se efetua a língua viva, tanto menos se é dela consciente" (ALMEIDA, FLICKINGER, ROHDEN, 2000, p. 123). O segundo momento é a ausência de um eu, o ato de falar parece não poder estar preso ao eu, a constituição é feita de nós, a linguagem precisa conceber "nós" para então tornar-se possível, assim, "quando dizemos “eu”, também já expressamos o tu (alteridade do eu) sem o qual eu não é" (ALMEIDA, 2002, p. 206). O terceiro momento é denominado universalidade da linguagem, é proposto que o ato da fala não tem fim, todos os diálogos são infinitos, é possível um instante de interrupção, mas não um esgotamento, cada interrupção carrega a possibilidade de reiniciar o diálogo, sob novas perspectivas. Os conceitos inerentes a linguagem dentro da hermenêutica filosófica de Gadamer como a universalidade, a centralidade e a inesgotabilidade marcam a finitude do ser e, por sua vez, marca ontologicamente a linguagem e o próprio ser.

É na linguagem que ocorre a fusão de horizontes, onde cada horizonte é constituído a partir da tradição na qual está inserido, bem como os pré-juizos, e essencialmente a hermenêutica é ligada às questões da linguagem, em especial, a linguagem escrita, ao tratar desde a mais simples interpretação no que tange uma conversação em que as palavras utilizadas possuem aspectos polissêmicos até a produção do discurso, o ato interpretativo tem a função de encontrar a real intencionalidade do texto dentro de um contexto polissêmico e isso ocorre a partir do jogo entre pergunta e resposta, ou seja, pelo diálogo. Cabe a linguagem o desvelar do mundo, isso significa que o processo hermenêutico em Gadamer abarca a experiência mundana, ou melhor, afirma Stein (2014, p. 212): “a compreensão de Gadamer é desenvolvida no contexto de um projeto que procura recuperar a historicidade da cultura e do mundo vivido". 
Ter na linguagem o papel central de sua hermenêutica significa percebê-la enquanto aberta para novas experiências, que lhe confere a possibilidade de finitude, a finitude necessária, pois arma historicamente o processo hermenêutico. Retomando o conceito de fusão de horizontes, de acordo com Almeida (2002) a fusão ocorre no processo dialógico da linguagem entre o "eu" e o "outro", ambos se projetam para o horizonte do outro com a finalidade de compreender o que lhe causa estranheza, ao entrar em contato com o outro, a intenção é recepcioná-lo, sem que o eu seja anulado, para que haja o alargamento das possibilidades diante desse acontecimento. Dessa forma, afirma Gadamer:

Percebemos agora que todo esse processo é um processo de linguagem. Não é por acaso que a verdadeira problemática da compreensão e a tentativa de dominá-la pela arte - o tema da hermenêutica - pertencem tradicionalmente ao âmbito da gramática e da retórica. A linguagem é o meio em que se realizam o acordo dos interlocutores e o entendimento sobre a coisa em questão. (GADAMER, 2016, p. 497).

\section{A concepção de verdade segundo Hans-Georg Gadamer}

O processo compreensivo acontece sob as bases da linguagem, portanto, carrega consigo a característica de ser dialógico, tornando possível a interação entre diferentes horizontes inseridos no decorrer da história, o que Gadamer nomeia como fusão de horizontes, possibilitando assim o aparecimento de uma nova compreensão. Tal processo, portanto, está imerso em uma tradição que sempre se localiza entre condições do passado, presente e a possibilidade de projeção do futuro.

A verdade acontece na hermenêutica gadameriana como resultado do processo compreensivo. A forma, portanto, que o autor trata da verdade em sua obra principal, nada mais é que o demonstrativo de como o conceito de verdade se movimenta. Gadamer inicialmente abandona o método cientifico para alcança-lo posteriormente, é traçado um grande questionamento em busca de conceber como se dá a experiência do acontecer da verdade que não dialoga mais com a objetividade relacionada ao âmbito cientifico, mas se encontra intimamente ligada a linguagem a partir de seu formato dialógico, que consiste na dinâmica de pergunta e resposta.

O autor propõe que o movimento do conceito de verdade vai do geral para o particular, onde estão localizadas as várias formas de conceber o acontecer da verdade, e assim, formam a compreensão. Sobre esse novo formato de concepção da verdade, afirma Ernildo Stain: "Temos 
uma verdade que acontece na história da hermenêutica, e ao mesmo tempo, nas três partes que compõem o livro: a verdade na arte, a verdade na história e a verdade na linguagem. Esse saber de modo algum é absoluto" (STAIN, 2014, p. 221).

Stain se refere a nova concepção de verdade exposta por Gadamer na obra Verdade e Método, cuja primeira parte trata o acontecer da verdade a partir da arte, tal experiência está intimamente ligada ao ser histórico, "é uma forma de autocompreender-se" (GADAMER, 2016, p. 149), essa autocompreensão da existência do ser histórico a partir da experiencia estética, lança questionamentos acerca da possibilidade de existência de um conhecimento proveniente da mesma. Desse modo, questiona o autor:

\begin{abstract}
Será que não deve haver nenhum conhecimento na arte? Não há também na experiência da arte uma pretensão de verdade, diversa daquela da ciência, mas certamente não inferior? E será que a tarefa da estética não está justamente em fundamentar que a experiência da arte é uma forma de conhecimento sui generis, certamente distinta daquela do conhecimento sensível que oferece a ciência os últimos dados, a partir dos quais ela constrói o conhecimento da natureza, também diferente de todo conhecimento racional da ética e de todo o conhecimento conceitual, mas mesmo assim sempre conhecimento, ou seja, mediação da verdade? (GADAMER, 2016, p.149-150).
\end{abstract}

Gadamer aposta em Hegel para fundamentar sua concepção de conhecimento dentro da experiência estética, e fazendo uso da forma ampla com que o autor concebeu a experiência é possível verificar a presença da verdade no processo de contato no Ser histórico experienciando a arte, tornando possível "justificar na própria experiência da arte o conhecimento da verdade" (GADAMER, 2016, p. 150). O acolhimento do pensamento de Hegel dentro da temática que concilia arte e verdade, também possibilitou florescer a questão da verdade na história, ou melhor, a crítica da consciência histórica promovida por Gadamer. A busca da verdade pela obra de arte marca o início da ampla discussão da obra no que tange a verdade no processo compreensivo das ciências do espirito.

Na segunda parte de Verdade e Método, intitulada “A extensão da questão da verdade à compreensão nas ciências do espirito" a temática em evidência é o conceito de verdade dentro da história. A partir da influência de Heidegger e o conceito de Facticidade, a hermenêutica gadameriana tem a historicidade do ser como ponto fulcral, o ser enquanto essencialmente histórico encontra-se imerso na construção de sentido e possui na história parte de sua estrutura de compreensão ligado ao fenômeno da tradição (SILVA, 1995). A experiência hermenêutica, portanto, abarca a tradição uma vez que a compreensão é intimamente ligada ao ser histórico. 
A tradição, identificada pelo autor como um conjunto de preconceitos, não subjectivos, que orientam a interpretação, funciona aqui de um modo decisivo, mas não dogmático, como o horizonte que permite a suscitação de novas questões e dos problemas em aberto desenhados pelo texto. Constitui-se como um acontecer ou processo histórico, a partir do modelo dialógico da fusão ou entrelaçamento de horizontes. (SILVA, 1995, p. 24).

É necessário visualizar a tradição enquanto uma área permeada pela dinâmica da précompreensibilidade (preconceito). Dessa forma, é possível afirmar que a:

Tradição significa justamente transmissão de algo, isto é, um acontecer de sentido que implica uma recepção não puramente passiva, mas sempre mediada, por uma tradição, logo por todo um efeito histórico de sentido, efeito que não tem aqui uma natureza não determinista nem casual. (SILVA, 1995, p.16).

Contida na tradição está o caráter histórico do ser, reiterando sua finitude e concebendo um processo interpretativo que não pode se livrar dos preconceitos. O fenômeno da compreensão engloba o conceito de fusão de horizontes, estabelece um diálogo entre o eu e o outro, portanto é um processo dialógico, no qual o eu e o outro devem estar abertos para ouvir, a finitude do ser garante igualmente uma interpretação finita e dessa forma corrobora o abrirse para o entrecruzar referente ao diálogo.

A terceira, e última, parte da obra é intitulada "A virada ontológica da hermenêutica no fio condutor da linguagem" a temática apresentada aborda o próprio solo ontológico de toda a experiência hermenêutica de Gadamer que é a linguagem. A busca da verdade sob o intermédio da linguagem conclui que o próprio processo compreensivo é permeado pela linguagem, portanto, é "pôr-se de acordo na linguagem e não transferir-se para o outro e reproduzir suas vivências" (GADAMER, 2016, p. 497). Por fim, verificamos que na medida em que concluímos o processo compreensivo, "estamos incluídos num acontecer da verdade e quando, de certo modo, queremos saber no que devemos crer, parece-nos que chegamos demasiado tarde" (GADAMER, 2016, p. 631).

O acontecer da verdade dentro da hermenêutica filosófica de Gadamer acontece sob uma objetividade que não compete ao âmbito cientifico, mas a partir da linguagem. Diante da estrutura circular do processo compreensivo, o modelo da dialética platônica surge como chave interpretativa para a experiência hermenêutica e a pergunta ganha papel de destaque em sua filosofia. Dessa forma "é preciso então que nos aprofundemos na essência da pergunta, se 
quisermos esclarecer em que consiste o modo peculiar de realização da experiência hermenêutica" (GADAMER, 2016, p. 473).

A hermenêutica gadameriana carrega a negatividade radical da pergunta sintetizada na docta ignorantia socrática: no saber que não sabe (GADAMER, 2016). O autor segue afirmando que o ato de perguntar necessita do interesse na pergunta, saber que não se sabe é importante para que a pergunta tenha sentido e abertura, que é o espaço para novas experiências (ALMEIDA, 2002). No que tange a finitude ontológica compreendida na questão da pergunta, Almeida (2002) afirma que:

Em nível ontológico, pode-se, então, afirmar que a pergunta tem sempre primazia sobre a resposta; nela se revela a negatividade produtiva que marca a experiência hermenêutica. Ao se fazer uma pergunta, mais do que qualquer resposta dada, o que surge é a experiência radical da finitude e a consciência de pertencimento a uma realidade linguística e histórica intransponíveis. (ALMEIDA, 2002, p. 176).

Essa relação com a pergunta é caminho para o entendimento de uma nova concepção acerca do conceito de verdade, trata-se de uma verdade compreensiva que procura abarcar as experiências ainda não alcançadas pelo modelo anterior de verdade proveniente do âmbito cientifico, Gadamer pretende demonstrar os limites desse antigo modelo e do próprio método cientifico. Essa verdade é resultado da relação da linguagem, enquanto suporte ontológico do fenômeno hermenêutico, com a tradição. É efetivamente proposto a unidade desses termos, pois é no entrecruzar desses conceitos que se revela a fonte de experiência de uma verdade não absoluta, uma verdade compreensiva que acontece sob diversas temáticas sem estar presa ao método cientifico. Como afirma Côrtes (2006, p. 281): “nem o método é caminho, fundamento ou morada da verdade; nem verdade consiste num substantivo feminino singular que guarda clara e inequívoca unidade de sentido".

Se a tradição possui um solo nele está inserido essencialmente a linguagem, como já fora exposto o conceito da tradição é essencial para o processo compreensivo, isso porque, possui com a linguagem estreita ligação. Dessa forma, afirma Gadamer:

A tradição de linguagem é tradição no sentido mais autêntico da palavra, ou seja, aqui não nos defrontamos simplesmente com um resíduo que se deve investigar e interpretar enquanto vestígio do passado. O que chegou a nós pelo caminho da tradição de linguagem não é o que restou, mas é transmitido, isto é, nos é dito - seja na forma de tradição oral imediata, onde vivem o mito, a lenda, os usos e os costumes, seja na forma da tradição escrita, cujos signos de certo modo destinam-se diretamente a todo e qualquer leitor que esteja em condições de os ler. (GADAMER, 2016, p. 504). 
O autor garante que é possível verificar a ligação mais importante entre tradição e linguagem em seu formato de escrita, sendo a tarefa primordial da hermenêutica encontrar o sentido de determinado texto, a interpretação do mesmo ganha maior importância, pois, pode ser compreendido por si mesmo. Nas palavras de Gadamer:

$\mathrm{Na}$ forma escrita todo o transmitido está simultaneamente presente para qualquer atualidade. Nela se dá uma coexistência de passado e presente única em seu gênero, na medida em que consciência presente tem a possibilidade de um acesso livre a tudo quanto tenha sido transmitido por escrito. A consciência que compreende, liberada de sua dependência da transmissão ora, que traz ao presente as notícias do passado, porém voltada imediatamente para a tradição literária, ganha uma possibilidade autêntica de avançar os limites e ampliar seu horizonte, enriquecendo assim seu próprio mundo com toda uma nova dimensão de profundidade. (GADAMER, 2016, p. 505).

Pensando a ligação da linguagem ao processo hermenêutico, negando de maneira enfática a questão do método como problema de tal processo, verifica-se que o ser histórico implica mais que uma razoável compreensão dos textos, adiciona-se a isso a abertura da possibilidade de reconhecimento de verdades. Dentro dessa lógica, na qual se movimenta o processo compreensivo, a verdade não escapa da abertura promovida pela pergunta, na medida em que há sempre uma reabertura do diálogo com novas perguntas, há também novas respostas. A investigação acerca da verdade apresenta o seguinte desfecho, de acordo com o autor de Verdade e Método:

No conjunto de nossa investigação mostrou-se que a certeza proporcionada pelo uso dos métodos científicos não é suficiente para garantir a verdade. Isso vale sobretudo para as ciências do espirito, mas de modo algum significa uma diminuição de sua cientificidade. Significa, antes, a legitimação da pretensão de um significado humano especial, que elas vêm reivindicando desde antigamente. $\mathrm{O}$ fato de que o ser próprio daquele que conhece também entre em jogo no ato de conhecer marca certamente o limite do "método", mas não o da ciência. O que o instrumental do "método" não consegue alcançar deve e pode realmente ser alcançado por uma disciplina do perguntar e do investigar que garante a verdade. (GADAMER, 2016, p. 631).

\section{Conclusão}

Este artigo se propôs a explicitar o papel da linguagem dentro da experiência hermenêutica, partindo da hipótese que gira em torno da relação de equivalência entre os conceitos de tradição e linguagem, e essa ligação revela ser a fonte do acontecer de uma verdade compreensiva. $\mathrm{O}$ autor percebe na linguagem todo o solo da experiência hermenêutica, ela é abertura e possibilidade de camuflar e desvelar o mundo. O acontecimento da abertura é 
apontado na historicidade do ser, onde experimentamos a finitude do ser que implica um processo compreensivo mediado por uma dinâmica da pré-compreensibilidade que antecede o processo, do qual não podemos nos livrar.

É fundamental para o fenômeno da compreensão reconhecer a dinâmica da précompreensibilidade tanto do eu como do outro, a experiência ocorre de maneira dialógica, dessa forma, ambos devem estar dispostos para abrir seu horizonte e abrigar um ao outro, pois, é nesse reconhecimento do outro que passamos a reconhecer a dinâmica e área limítrofe que precede nossa compreensão. Assim, é possível notar que a experiência hermenêutica de Gadamer é essencialmente construir uma experiência com o outro. Com isso, falamos de uma verdade histórica, que tem um horizonte determinado, contradizendo uma verdade absoluta proveniente de um método, e corroborando o conceito de verdade enquanto algo construído e condicionado historicamente. Há sempre uma intenção na fala dos sujeitos dentro do diálogo, isso não significa que os mesmos tenham total controle sobre suas verdades, o conteúdo que se encontra nos discursos de cada participante do diálogo nada mais é que a exposição das verdades resultantes da estreita ligação entre tradição e linguagem na qual estão imersos.

\section{REFERÊNCIAS BIBLIOGRÁFICAS}

ALMEIDA, C. L. S. Hermenêutica e Dialética: Dos estudos platônicos ao encontro com Hegel. Porto Alegre: EDIPUCRS, 2002.

ALMEIDA, C. L. S.; FLICKINGER, Hans-Georg.; ROHDEN, Luiz. Hermenêutica filosófica: nas trilhas de Hans-Georg Gadamer. Porto alegre: EDIPUCRS, 2000.

BOECKH, August. Encyklopädie und Methodologie der philologischen Wissenschaften. 2. Ed. - Springer Fachmedien Wiesbaden Gmbh, 1886.

CÔRTES, Norma. Descaminhos do método: notas sobre história e tradição em Hans-Georg Gadamer. Varia hist., Belo Horizonte, v. 22, n. 36, p. 274-290, dez. 2006.

DILTHEY, Wilhelm. O Surgimento da Hermenêutica. Numem, Juiz de Fora, v. 2, n.1. p.1132, jan./jul., 1999.

DROYSEN, Johann Gustav. Manual de Teoria da História. Petrópolis. RJ: Vozes, 2009.

FANTON, Marcos.; ZEIFERT, Emanuel Bagetti. Epistemologia, ontologia e linguagem em Verdade e Método: Uma exposição crítica. Perspectiva Filosófica. Recife, v. 41, n. 2, p. 102115. 2014. 
GADAMER, Hans-Georg. Verdade e Método I - traços fundamentais de uma hermenêutica filosófica. Petrópolis, RJ: Vozes. Editora universitária são Francisco, 2015.

GRONDIN, Jean. Introdução à Hermenêutica Filosófica. São Leopoldo: Ed. Unisinos, 1999.

PALMER, Richard E. Hermenêutica. Lisboa: edições 70, 1969.

RICOEUR, P. O conflito das interpretações. São Paulo: Imago, 1978.

SILVA, M. L. F. O preconceito em H.-G. Gadamer: sentido de uma reabilitação. Lisboa: Fundação Calouste Gulbenkian, 1995.

SCHLEIERMACHER, Friedrich. Hermenêutica. Petrópolis: Vozes, 1999.

STEIN, Ernildo. Gadamer e a consumação da hermenêutica. Problemata: revista internacional de filosofia. Porto Alegre, v. 5, n. 1, p. 204-226, 2014.

STEGMULLER, Wolfgang. A filosofia contemporânea. Rio de Janeiro, ed: forense universitária, 2012.

ZABEU, Gabriela Miranda. Preconceito e Diálogo: ética e ontologia na fusão de horizontes. Florianópolis, 2014. 130f. Dissertação (Mestrado em Filosofia) - Universidade Federal de Santa Catarina, Centro de Filosofia e Ciências Humanas, Programa de Pós-graduação em Filosofia, Florianópolis, 2014.

Artigo recebido em: 29/07/2020

Artigo aprovado em: 05/10/2020 